\title{
Successful Treatment for Adult Precursor B-Cell Lymphoblastic Lymphoma Involving Central Nervous System Monitored by ${ }^{18}$ F-Fluorodeoxyglucose PET/CT Imaging
}

\author{
Xiang Shi ${ }^{1 \dagger}$, Weiyan Zhou ${ }^{2 \dagger}$, Mengqiao $\mathrm{Xu}^{1}$, Tao Hua ${ }^{2}$ and Yihui Guan ${ }^{2,3 *}$ \\ ${ }^{1}$ Department of Ophthalmology, School of Medicine, Shanghai General Hospital, Shanghai JiaoTong University, Shanghai, \\ China, ${ }^{2}$ PET Center, Huashan Hospital, Fudan University, Shanghai, China, ${ }^{3}$ Institute of Integrative Medicine, Fudan \\ University, Shanghai, China
}

OPEN ACCESS

Edited by:

Freimut Dankwart Juengling, Universität Bern, Switzerland

Reviewed by:

Paul Thomas Winnard $\mathrm{J}$ Johns Hopkins University,

United States

Xudong Shen,

Guizhou Medical University, China

*Correspondence:

Yihui Guan

guanyihui@fudan.edu.cn

tThese authors have contributed equally to this work

Specialty section:

This article was submitted to Cancer Imaging and Image-directed Interventions,

a section of the journa

Frontiers in Oncology

Received: 22 October 2019

Accepted: 26 February 2020

Published: 24 March 2020

Citation:

Shi X, Zhou W, Xu M, Hua T and Guan Y (2020) Successful Treatment

for Adult Precursor B-Cell

Lymphoblastic Lymphoma Involving Central Nervous System Monitored by

${ }^{18}$ F-Fluorodeoxyglucose PET/CT Imaging. Front. Oncol. 10:334. doi: 10.3389/fonc.2020.00334
Precursor B-cell lymphoblastic lymphoma (PBLL) is a rare subtype of non-Hodgkin lymphoma originating from B-cell precursors. PBLL, as a solitary mass lesion affecting the central nervous system without leukemic disease at presentation, is quite uncommon. Here we report a rare PBLL case with Philadelphia chromosome positivity. The 44-year-old male presented a solitary bulky mass primarily involving the left frontotemporal lobes and extended into the infratemporal fossa. Pretreatment PET/CT imaging showed avid ${ }^{18}$ F-fluorodeoxyglucose ( ${ }^{18} \mathrm{~F}-\mathrm{FDG}$ ) uptake of the lesion. By aggressive chemotherapy and imatinib maintenance treatment, the patient achieved and remained in complete remission on another two consecutive PET/CT imaging follow-ups.

Keywords: precursor B-cell lymphoblastic lymphoma, fluorodeoxyglucose (FDG), PET/CT, Philadelphia chromosome, imatinib

\section{CASE PRESENTATION}

A previously healthy 44-year-old male presented with chronic vision loss of the left eye for 1 month and complained about progressive distending pain of his left orbital region. Ophthalmic examinations found that his left eye was exophthalmic with positive relative afferent pupillary defect (RAPD), which indicated optic nerve injury. The best-corrected visual acuity (BCVA) of his left eye was 0.4. Unenhanced orbital CT detected an intracranial mass lesion with concurrent extracranial invasion. Malignancy was highly suspected. The patient underwent brain MRI and whole-body 18 F-fluorodeoxyglucose $\left({ }^{18}\right.$ F-FDG) PET/CT.

MRI revealed a heterogeneous enhanced mass lesion with meningeal and adjacent frontaltemporal lobes involvement (Figure 1A). The mass lesion showed heterogeneous hyperdensity on CT images, and peripheral edema was observed (Figure 1B). ${ }^{18} \mathrm{~F}$-FDG PET/CT showed intense FDG uptake with maximum standardized uptake value $\left(\mathrm{SUV}_{\max }\right)$ of 12.0 in the left frontaltemporal lobes (Figure 1C). No evident bone marrow (BM) involvement was observed on ${ }^{18} \mathrm{~F}$-FDG PET/CT (Figure 1D). Lymphadenopathy and hepatosplenomegaly were also absent.

A biopsy tissue specimen of about $5 \times 15 \mathrm{~mm}$ was obtained under MRI guidance for pathological diagnosis. Immunohistochemical staining showed that the oval-round tumor cells were positive for paired box 5 (PAX5), terminal deoxynucleotidyl transferase (TdT), and CD79a, which indicated 

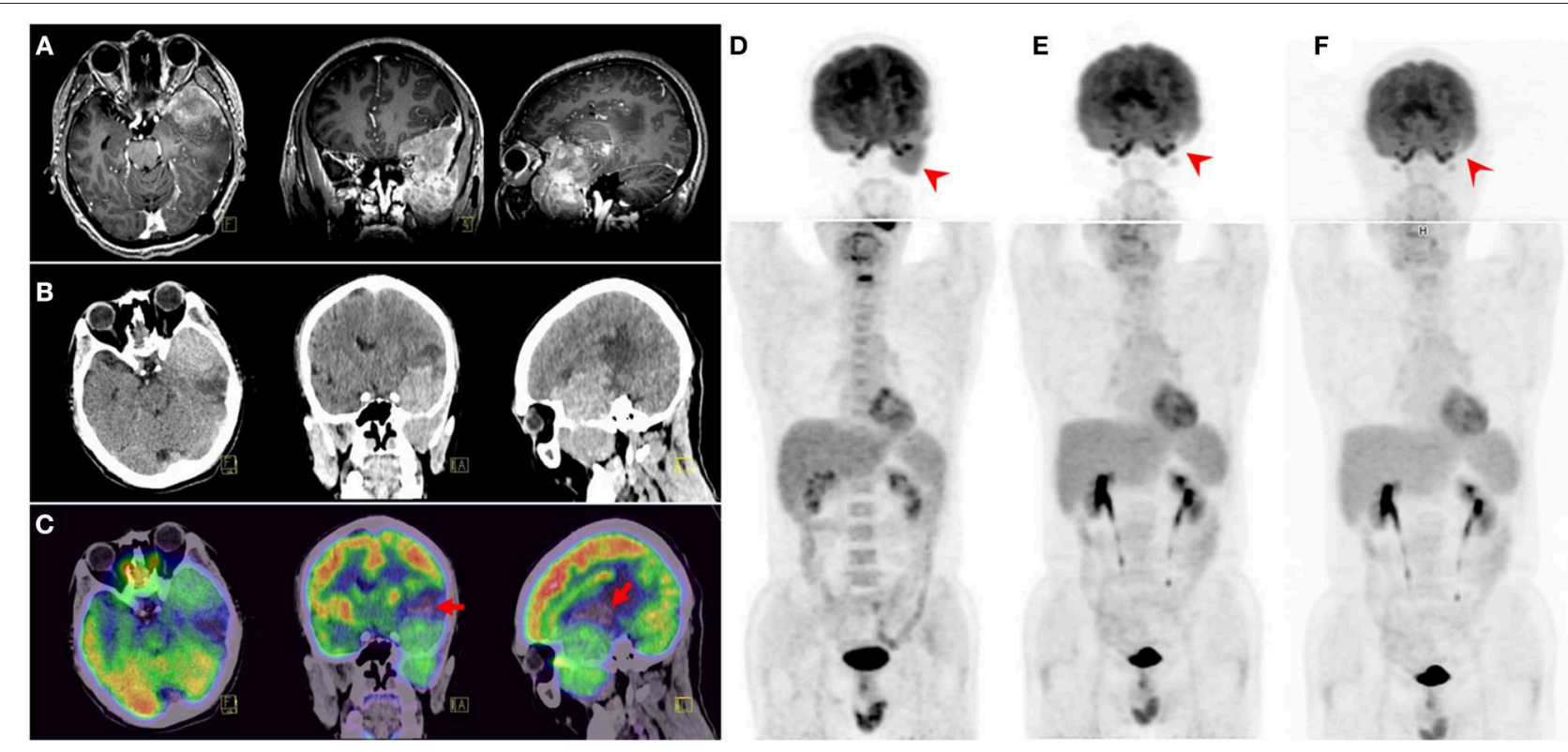

FIGURE 1 | MRI revealed a heterogeneous enhanced mass lesion with meningeal and adjacent frontal-temporal lobes involvement (A). CT displayed a heterogeneous

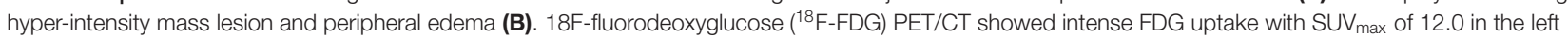
frontal-temporal lobes. Part of the lesion was naive with FDG uptake (arrows) (C), which could be caused by possible intratumoral hemorrhage. Adjacent skull base bone destruction and extracranial extension to the left infratemporal fossa were also observed. Maximum intensity projection (MIP) view of pretreatment ${ }^{18} \mathrm{~F}$-FDG PET/CT (D) showed the solitary bulky mass. Two consecutive ${ }^{18}$ F-FDG PET/CT follow-ups (E,F) demonstrated complete remission.

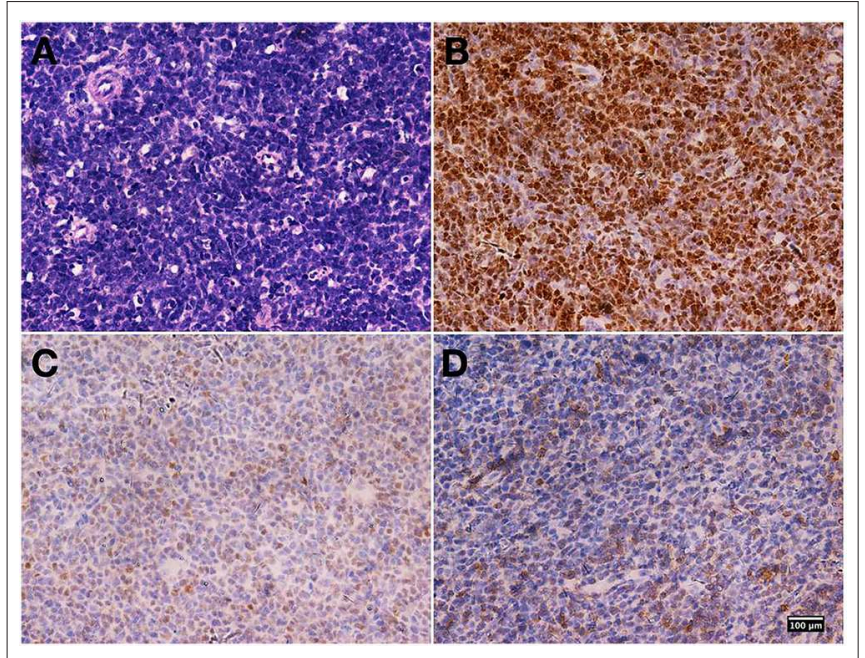

FIGURE 2 | Biopsy specimen pathological findings. Hematoxylin and eosin staining revealed diffusely distributed atypical lymphoid cells (A).

Immunohistochemical staining showed that the oval-round tumor cells were positive for paired box 5 (PAX5) (B), terminal deoxynucleotidyl transferase

(TdT) (C), and CD79a (D). Magnification, $\times 400$ for all.

the diagnosis of precursor B-cell lymphoblastic lymphoma (PBLL) (Figure 2). Ki-67 staining showed that the proportion of positive tumor cells was $\sim 70 \%$. BM aspiration and peripheral blood cell counts excluded acute lymphoblastic leukemia (ALL). Further karyotyping and analysis of breakpoint cluster region $(\mathrm{BCR}) /$ Abelson murine leukemia $(\mathrm{ABL}) 1$ genes (22q11/9q34) for biopsy specimen were positive at a level of $71 \%$, indicating a possibly promising treatment of tyrosine kinase inhibitors (TKIs).

After the diagnosis of PBLL was confirmed, the patient received six-cycle intravenous chemotherapy with hyperfractionated cyclophosphamide, vincristine, Adriamycin, and dexamethasone (hyper-CVAD) plus rituximab regimen. Additional intrathecal chemotherapy (methotrexate $10 \mathrm{mg}$, cytosine arabinoside $50 \mathrm{mg}$, dexamethasone $5 \mathrm{mg}$ ) for eight cycles was applied. A follow-up ${ }^{18}$ F-FDG PET/CT scan demonstrated a remarkable metabolism decline of the lesion after the treatment (Figure 1E). After remission, the patient received maintenance therapy with imatinib. A third ${ }^{18} \mathrm{~F}$ FDG PET/CT scan 2-years after initial diagnosis also showed no relapse (Figure 1F). No abnormal signs were found on peripheral blood and BM aspiration smears, BM flow cytometry, cerebrospinal fluid (CSF) analyses, ultrasonography, MRI, and skeletal scintigraphy examinations.

\section{DISCUSSION AND CONCLUSIONS}

PBLL is a rare subtype of non-Hodgkin lymphoma originating from B-cell precursors, as the name suggests. PBLL patients could have nodal or extranodal involvement, and BM involvement is $<25 \%(1,2)$. Precursor lymphoblastic lymphoma (PLL) can be of B-cell or T-cell lineage, and the clinical manifestation varies significantly. Precursor T-cell lymphoblastic lymphoma (PTLL) is more common in children, mainly presented with an anterior mediastinal mass. PBLL only accounts for $10-25 \%$ of all 
PLL and typically presents with subcutaneous, soft tissue, bone, and lymph node disease in children or young adults. Primary uncommon lesions of PBLL in testicles, localized skin, pancreas, and musculoskeletal system on ${ }^{18}$ F-FDG PET imaging were reported, with $\mathrm{SUV}_{\max }$ ranging from 3.7 to 19.1 (3-9). Besides that, there are also case reports with initial symptoms of ovaries, retroperitoneum, tonsil, uterus, stomach, colon, mediastinum, and both lytic and blastic bone lesions (10-13).

PBLL presenting as one solitary mass lesion affecting the central nervous system (CNS) without leukemic disease is quite rare but could be more aggressive with a worse prognosis. Despite prophylactic treatment, some PBLL patients still relapse in the CNS. Diffuse leptomeningeal infiltration after the confirmation of diagnosis or relapse is also common. Presentation of leptomeningeal lymphoblastic lymphoma newly diagnosed in a 6-year-old boy was reported (14). However, a mass lesion affecting the CNS without leukemic disease as an initial manifestation of PBLL is rare. To our knowledge, there is only one case report of a PBLL patient who presented with compression of spinal cord mass lesion (15). Differential diagnoses, including malignant meningioma, sarcomas of muscle or bone origin, and metastatic tumors, should be considered for this patient.

In this case, we were able to exclude myeloid, T-cell, and natural killer $(\mathrm{NK}) / \mathrm{T}$-cell lineage because the malignant cells did not express the myeloid marker myeloperoxidase, the T-cell marker CD3, or the NK/T-cell marker CD56. By contrast, this patient's immunohistochemistry stain showed positive B-cell markers, including PAX5, TdT, and CD79a, but absent for CD20, which indicated the origin of B-cell lineage. Philadelphia $(\mathrm{Ph})$ chromosomes present in 90-95\% of chronic lymphocytic leukemia (CML) patients, but less frequently in PBLL/ALL patients. Ph-positive PBLL is rare

\section{REFERENCES}

1. Cortelazzo S, Ponzoni M, Ferreri AJ, Hoelzer D. Lymphoblastic lymphoma. Crit Rev Oncol Hematol. (2011) 79:330-43. doi: $10.1016 /$ j.critrevonc.2010.12.003

2. Nathwani BN, Diamond LW, Winberg CD, Kim H, Bearman RM, Glick JH, et al. Lymphoblastic lymphoma: a clinicopathologic study of 95 patients. Cancer. (1981) 48:2347-57. doi: 10.1002/10970142(19811201)48:11<2347::aid-cncr2820481102>3.0.co;2-x

3. Garcia AV, Alobeid B, Traina JM, Chen SS, Weiner MA, Middlesworth W. Isolated primary testicular B lymphoblastic lymphoma: an unusual presentation. J Pediatr Hematol Oncol. (2013) 35:e88-90. doi: 10.1097/MPH.0b013e318271c470

4. Park DA, Park SG, Kim SW. Solitary lymphoblastic lymphoma of the thoracic spine. J Korean Neurosurg Soc. (2012) 52:5646. doi: 10.3340/jkns.2012.52.6.564

5. Kaygusuz I, Toptas T, Guven A, Firatli-Tuglular T, Tecimer T, Bayik M. Precursor B cell lymphoblastic lymphoma presenting as a solitary bone tumor: a case report and review of the literature. Int J Hematol. (2010) 92:757-61. doi: 10.1007/s12185-010-0715-5

6. Cho SY, Lee SS, Back DH, Lim KA, Lee YR, Kang HJ. Primary cutaneous Bcell lymphoblastic lymphoma in an elderly man. Korean J Hematol. (2011) 46:283-6. doi: 10.5045/kjh.2011.46.4.283

7. Lam PD, Kuribayashi A, Sakamoto J, Nakamura S, Harada H, Kurabayashi T. Imaging findings of childhood B-cell lymphoblastic lymphoma in the
(16). Based on the patient's cell/molecular genetic changes and the treatment of Ph-chromosomal-positive ALL, imatinib was added at the maintaining time of chemotherapy to obtain better efficacy. The patient remained in complete remission at the last follow-up.

This case exemplifies the importance of cytogenetic or molecular genetic analysis for the diagnosis and treatment of PBLL/ALL. As a molecular and functional imaging method, ${ }^{18} \mathrm{~F}-$ FDG PET/CT could facilitate lesion detection and hematologic tumor evaluation after aggressive chemotherapy and TKIs maintaining intervention.

\section{DATA AVAILABILITY STATEMENT}

All datasets generated for this study are included in the article/supplementary material.

\section{ETHICS STATEMENT}

The study was approved by the Human Ethics Review Committee of Huashan Hospital, Fudan University. A written informed consent to publish the report and associated medical images was obtained from the patient.

\section{AUTHOR CONTRIBUTIONS}

All authors listed have made a substantial, direct and intellectual contribution to the work, and approved it for publication.

\section{FUNDING}

This study was supported by the National Natural Science Foundation of China (Project No. 81571345). mental region: a case report. Dentomaxillofac Radiol. (2017) 46:20160313. doi: $10.1259 / \mathrm{dmfr} .20160313$

8. Nakaji S, Hirata N, Shiratori T, Kobayashi M, Fujii H, Ishii E, et al. A case of primary pancreatic lymphoblastic lymphoma diagnosed by endoscopic ultrasound-guided fine-needle aspiration. Clin J Gastroenterol. (2014) 7:1804. doi: 10.1007/s12328-014-0462-x

9. Liu Z, Yang X, Liu J, Yang J. FDG PET/CT demonstrated precursor B-cell lymphoblastic lymphoma in a pediatric patient with hemophilia B. Clin Nucl Med. (2019) 44:683-5. doi: 10.1097/RLU.0000000000002582

10. Iravani S, Singleton TP, Ross CW, Schnitzer B. Precursor B lymphoblastic lymphoma presenting as lytic bone lesions. Am J Clin Pathol. (1999) 112:836-43. doi: 10.1093/ajcp/ 112.6 .836

11. Koliopoulos G, Parkin D, Paraskevaidis E. A case of B-cell lymphoblastic lymphoma involving the uterus. Eur J Gynaecol Oncol. (2002) 23:113-4.

12. Lin P, Jones D, Dorfman DM, Medeiros LJ. Precursor B-cell lymphoblastic lymphoma: a predominantly extranodal tumor with low propensity for leukemic involvement. Am J Surg Pathol. (2000) 24:1480-90. doi: 10.1097/00000478-200011000-00003

13. Maitra A, McKenna RW, Weinberg AG, Schneider NR, Kroft SH. Precursor B-cell lymphoblastic lymphoma. A study of nine cases lacking blood and bone marrow involvement and review of the literature. Am J Clin Pathol. (2001) 115:868-75. doi: 10.1309/Q5GV-3K00-WAC6-BBUB

14. Abla O, Naqvi A, Ye C, Bhattacharjee R, Shago M, Abdelhaleem M, et al. Leptomeningeal precursor B-cell lymphoblastic lymphoma in a child with 
minimal bone marrow involvement. J Pediatr Hematol Oncol. (2004) 26:46972. doi: 10.1097/00043426-200407000-00015

15. Khalid I, Rival J, Salama ME, Banghar PK, Janakiraman N. Unusual presentations of hematologic malignancies: CASE 2. Precursor B-cell lymphoblastic lymphoma presenting as spinal cord compression. J Clin Oncol. (2004) 22:1331-3. doi: 10.1200/JCO.2004. 05.060

16. Boddu P, Yin CC, Kanagal-Shamanna R, Tang G, Thakral B, Kadia T, et al. An unsuspected finding of $t(9 ; 22)$ : a rare case of philadelphia chromosomepositive B-lymphoblastic lymphoma. Case Rep Hematol. (2017) 2017:2413587. doi: $10.1155 / 2017 / 2413587$
Conflict of Interest: The authors declare that the research was conducted in the absence of any commercial or financial relationships that could be construed as a potential conflict of interest.

Copyright (๑) $2020 \mathrm{Shi}, \mathrm{Zhou}, \mathrm{Xu}$, Hua and Guan. This is an open-access article distributed under the terms of the Creative Commons Attribution License (CC BY). The use, distribution or reproduction in other forums is permitted, provided the original author(s) and the copyright owner(s) are credited and that the original publication in this journal is cited, in accordance with accepted academic practice. No use, distribution or reproduction is permitted which does not comply with these terms. 